D.O.I.:10.3895/S1808-04482006000200008

\title{
A METODOLOGIA KAIZEN NA CONDUÇÃO DE PROCESSOS DE MUDANÇA EM SISTEMAS DE PRODUÇÃO ENXUTA
}

\section{THE KAIZEN METHODOLOGY IN THE CONDUCTION OF CHANGE PROCESSES ON LEAN MANUFACTURING SYSTEMS}

\author{
Cesar Augusto Campos de Araujo ; Antonio Freitas Rentes ${ }^{2}$ \\ ${ }^{1}$ Engineering School of São Carlos - EESC - São Carlos - Brasil cesar@hominiss.com.br \\ ${ }^{2}$ Engineering School of São Carlos - EESC - São Carlos - Brasil rentes@sc.usp.br
}

\begin{abstract}
Resumo
Muitas empresas têm buscado implementar os conceitos, técnicas e ferramentas da Produção Enxuta, principalmente, pela expectativa dos ganhos dramáticos já relatados na literatura em vários aspectos, tais como: lead-time interno, estoque em processo, aumento de produtividade, etc. No entanto, em muitos casos, a principal dificuldade encontrada não reside somente no desenvolvimento do sistema enxuto, mas na forma de condução efetiva da mudança no chão-dafábrica. O objetivo deste artigo é mostrar a aplicação e implementação dos conceitos de produção enxuta por meio da metodologia Kaizen em uma empresa do setor médico-odontológico. Serão apresentados os conceitos utilizados no processo de implantação, bem como alguns resultados e conclusões obtidas.
\end{abstract}

Palavras-chave: produção enxuta, kaizen, mudança organizacional.

\section{Introdução}

De acordo com WOMACK, JONES E ROOS (1992), após a segunda guerra mundial a indústria japonesa desenvolveu um conjunto de novas práticas de manufatura que alavancaram sua competitividade global: trata-se das técnicas da produção enxuta.

Para WOMACK \& JONES (1998), a produção enxuta busca identificar e eliminar sistematicamente desperdícios na cadeia produtiva, sendo desperdício definido como qualquer atividade que absorve recursos e não cria valor. Dentre os principais tipos de desperdícios, podemos destacar: superprodução, tempos de espera (de pessoas e/ou equipamentos), transporte excessivo de materiais, processos inadequados, erros que exijam retificação, inventário desnecessário, movimentação de pessoas, etc.

Segundo HINES \& TAYLOR (2000), os princípios da produção enxuta são: 
- Especificar o que gera e o que não gera valor sob a perspectiva do cliente. Ao contrário do que tradicionalmente se faz, não se deve avaliar sob a óptica da empresa ou de seus departamentos;

- Identificar todos os passos necessários para produzir o produto ao longo de toda a linha de produção, de modo a não serem gerados desperdícios;

- Promover ações com o objetivo de criar um fluxo de valor contínuo, sem interrupções, ou esperas;

- Produzir somente nas quantidades solicitadas pelo consumidor;

- Esforçar-se para manter uma melhoria contínua, procurando a remoção de perdas e desperdícios.

Além dos princípios citados, a produção enxuta lança mão de algumas ferramentas com o intuito de otimizar o processo produtivo nas empresas, entre elas: o Mapa do Fluxo de Valor (MFV), o Heijunka Box, o Kanban, etc. A seguir, será feita uma breve discussão sobre a técnica de implementação conhecida como Kaizen, ferramenta utilizada no processo de implantação de melhorias na empresa em questão.

\section{Principais conceitos e técnicas da metodologia Kaizen e Evento Kaizen}

Kaizen significa a melhoria contínua de um fluxo completo de valor ou de um processo individual, a fim de se agregar mais valor com menos desperdício.

Segundo ROTHER \& SHOOK (1999), há dois níveis de kaizen:

- Kaizen de fluxo: ou de sistema, que enfoca no fluxo de valor, dirigido ao gerenciamento;

- Kaizen de processo: que enfoca em processos individuais, dirigido às equipes de trabalho e líderes de equipe.

Figura 1 - Dois níveis de kaizen

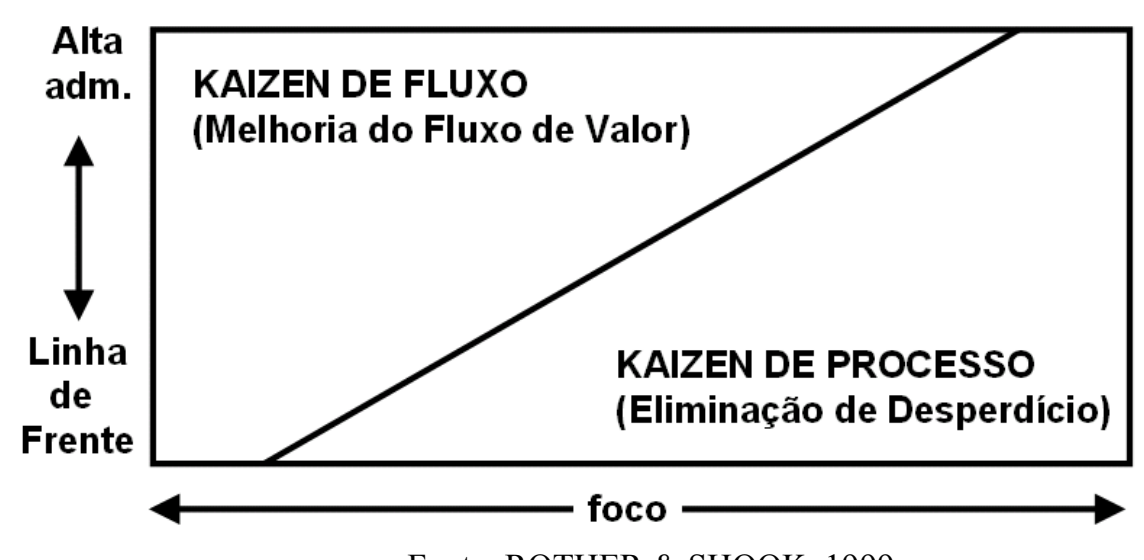

Fonte: ROTHER \& SHOOK, 1999 
Kaizen são esforços de melhoria contínua, executados por todos, sendo que o seu foco central é a busca pela eliminação dos desperdícios. Já a definição de um Evento Kaizen pode ser compreendida como sendo um time dedicado a uma rápida implantação de um método ou ferramenta da manufatura enxuta, em uma área em particular e em um curto período de tempo.

SMEDS (1994) afirma que a reorganização da manufatura de acordo com os princípios de produção enxuta pode disparar uma mudança organizacional radical, com uma nova estrutura, estratégia e cultura. O gerenciamento da demanda inicia-se a partir de uma visão estratégica seguida de fases como: análise e modelagem do estado atual, identificação de problemas e oportunidades, experimentos e escolha do estado futuro, implementação da mudança e estabilização do novo modelo de operação.

Apesar de muitas empresas de diversos setores terem alcançado benefícios significativos com a adoção dos conceitos de produção enxuta, muitos gerentes têm se complicado nas técnicas ao tentar implantar partes isoladas de um sistema enxuto sem entender o todo (fluxo e impactos sistêmicos na organização) (ARAUJO, 2004).

Mudanças, ainda que sejam para melhor, são difíceis para a maioria das pessoas. Mas, quanto mais as pessoas sabem sobre o que está acontecendo, torna-se mais fácil lidar com as expectativas e ansiedades que acompanham grandes mudanças. TAPPING ET. AL. (2002) apresentam algumas recomendações para o gerenciamento e enfrentamento dos contornos existentes em processos de mudança, especialmente aqueles em implementações de Sistemas de Produção Enxuta:

- Comunicar, comunicar, comunicar: assegure-se de que todos (não apenas os envolvidos diretamente na área em que ocorre o evento kaizen) saibam o que está ocorrendo, e o porquê. Uma breve explanação do líder do time de projeto, ou do supervisor da área, no início do turno de trabalho pode ser o necessário e suficiente para assegurar às pessoas de que ninguém os está privando de informações sobre o que está se passando;

- Identifique comportamentos negativos no início da implantação: se alguém não estiver participando, ou demonstrando comportamento negativo, fale com esta pessoa em particular. Ouça suas preocupações e aja no sentido de resolvê-las. Ouça ativamente o que as pessoas têm a dizer, com preocupação genuína. Então, responda. Explique como os esforços de mudança irão tornar a empresa mais forte, o que irá tornar o futuro de todos potencialmente mais próspero e seguro. Se possível, assegure às pessoas que ninguém irá perder seu emprego como decorrência direta da melhoria do fluxo;

- Não deixe um problema parar o processo: Talvez, um problema inesperado torne impossível a execução completa do evento kaizen. Conheça o problema, e re-programe o evento para o primeiro momento possível após o problema ser sanado. Não interprete o 
atraso como uma falha, mas como um desvio presente na maioria das jornadas ambiciosas;

- Considere cada evento kaizen um experimento: imagine que se esteja promovendo o desenvolvimento e implantação de uma célula, mas subestimou-se o tempo necessário para a execução e não foi feito estoque de segurança suficiente para o período todo da implantação. Então, precisa-se lutar e interromper momentaneamente o processo de celularização para que a linha de montagem do cliente não pare. Talvez, no próximo evento kaizen de desenvolvimento e implantação de uma célula, prefira-se usar um final de semana. Ou seja, alguns "erros" serão cometidos no processo. Aprenda com eles e caminhe adiante;

- Recompense e reconheça o esforço das pessoas: isto pode significar o aprimoramento da confiança mútua e do respeito. Pessoas, na maioria das vezes, motivam-se ao serem recompensadas de alguma forma: reconhecimento público, ganhos materiais ou status desejados;

- Esteja presente: o gerente do fluxo de valor, líder do projeto, e alta gerência devem ir ao chão-de-fábrica com regularidade de modo a encorajar os colaboradores e descobrir o que eles podem fazer para apoiar os esforços de mudança;

- Seja flexível: eventos inesperados irão, muito provavelmente acontecer. Mas, flexibilidade, combinada com foco e comprometimento, irão prevalecer, mais cedo ou mais tarde.

A seguir, será apresentada a aplicação da metodologia de Evento Kaizen para implantação de conceitos de Manufatura Enxuta em uma indústria do setor médico-odontológico. Serão apresentadas as etapas envolvidas e os resultados obtidos.

\section{Aplicação da metodologia kaizen em uma situação real}

A aplicação aqui descrita foi realizada em uma empresa localizada no interior do estado de São Paulo, que produz equipamentos odontológicos, sendo a maior fabricante nacional, atendendo mais da metade do mercado com mais 100 diferentes produtos. Seus principais produtos são consultórios odontológicos compostos por cadeira, equipo e unidades, equipamentos de raios-X e diversos outros acessórios.

O caso em questão compreende uma parte de um projeto de escopo amplo de mudança na direção da mentalidade enxuta na empresa. Algumas atividades precederam as atividades aqui descritas, dentre as quais: identificação de famílias de produtos e componentes, desenho da situação atual (inicialmente encontrada na empresa), desenvolvimento da situação futura para alguns destes 
componentes e implantação efetiva de algumas ferramentas para certas famílias (5S, produção puxada por cartões kanban, implantação de células de manufatura, etc.);

No entanto, na fase seguinte do projeto, aqui descrita, caminha-se na direção de estender as mudanças para todas as famílias de produtos, com a formação de uma visão futura idealizada para toda a empresa.

Para a realização do evento kaizen descrito, que foi aplicado na área de montagem de um dos produtos da empresa, atenção especial foi voltada à formação da Equipe (Time de Kaizen), de forma a ser composta por:

- Pessoas especialistas nos processos da área;

- Pessoas relacionadas à área (clientes e/ou fornecedores internos);

- Pessoas de fora da área (com o intuito de disseminação de conceitos e cultura);

- Facilitadores / coordenadores;

- Líderes;

- Especialistas / assessores externos (presentes sempre que solicitado pela equipe);

Neste caso, a equipe foi composta por um operador da linha de montagem do produto em questão, um especialista em métodos e processos, um operador do setor de usinagem (fornecedor interno), um operador do setor de pintura, e o líder / supervisor do fluxo em questão, que atuou com o papel de líder do time de kaizen.

O desenvolvimento do evento kaizen descrito deu-se conforme o modelo apresentado na figura a seguir:

Figura 2 - Planejamento do evento kaizen

\begin{tabular}{|c|c|c|c|c|c|}
\hline & SEG & TER & QUA & QUI & SEX \\
\hline INH $\tilde{\AA}$ & TREINAMENTO & AÇÃO DO KAIZEN & $\begin{array}{c}\text { IMPLEMENTAÇÃO } \\
\text { E TESTE }\end{array}$ & TREINAMENTO & APRESENTAÇÃO \\
\hline & PLANEJAMENTO & AÇÃO DO KAIZEN & $\begin{array}{l}\text { APRIMORAMENTO } \\
\text { EAJUSTES }\end{array}$ & CONSOLIDAÇÃO & CELEBRAÇÃO \\
\hline
\end{tabular}

No primeiro período do evento, a equipe designada participou de um treinamento que envolveu os principais conceitos da metodologia kaizen e alguns dos elementos da manufatura enxuta que poderiam ser utilizados durante os trabalhos.

Este treinamento enfatizou a importância do foco da equipe na missão a ser cumprida, no período de tempo designado (cinco dias), com dedicação exlusiva a esta tarefa, ou seja, os membros foram excluídos das tarefas que operavam rotineiramente.

Enfatizou-se a utilização desta estratégia centralizada em times de implementação de kaizens, mas preocupou-se com uma formal comunicação do processo a todos os membros da organização (gerência, área administrativa e demais setores fabris). Ou seja, o processo envolvia 
(direta e/ou indiretamente) vários níveis hierárquicos da organização, uma vez que o time de kaizen passou a ter prioridade no uso de recursos da fábrica (p.e. empilhadeiras, serviços de pintura, estamparia, etc.), e na coleta de informações, sempre que necessário.

A equipe foi destacada dos demais membros da empresa por meio do uso de um uniforme destacado em cor diferente da usual (colete amarelo) com a inscrição kaizen.

No período de planejamento, foram definidos os objetivos principais do time, que foram a implantação da programação puxada por meio de cartões kanban para, pelo menos, cinquenta itens, e a melhoria do layout na área de montagem, visando eliminação ou redução de desperdícios.

Durante este período também foi feito um breve levantamento da situação atual do setor (incluindo detalhamento do layout atual), bem como a divisão das tarefas entre os membros da equipe e a definição formal do cronograma de atividades.

As ações do kaizen (períodos seguintes) envolveram os seguintes aspectos:

Organização da área de trabalho: envolveu a identificação dos itens utilizados, a separação destes itens e a definição dos locais de armazenamento dos mesmos. Foram contruídos e implantados quadros de ferramentas para os diversos postos de trabalho (quadro sombra), além da preparação para demarcação das áreas de trabalho.

Figura 3 - Exemplos de melhorias do aspecto de organização

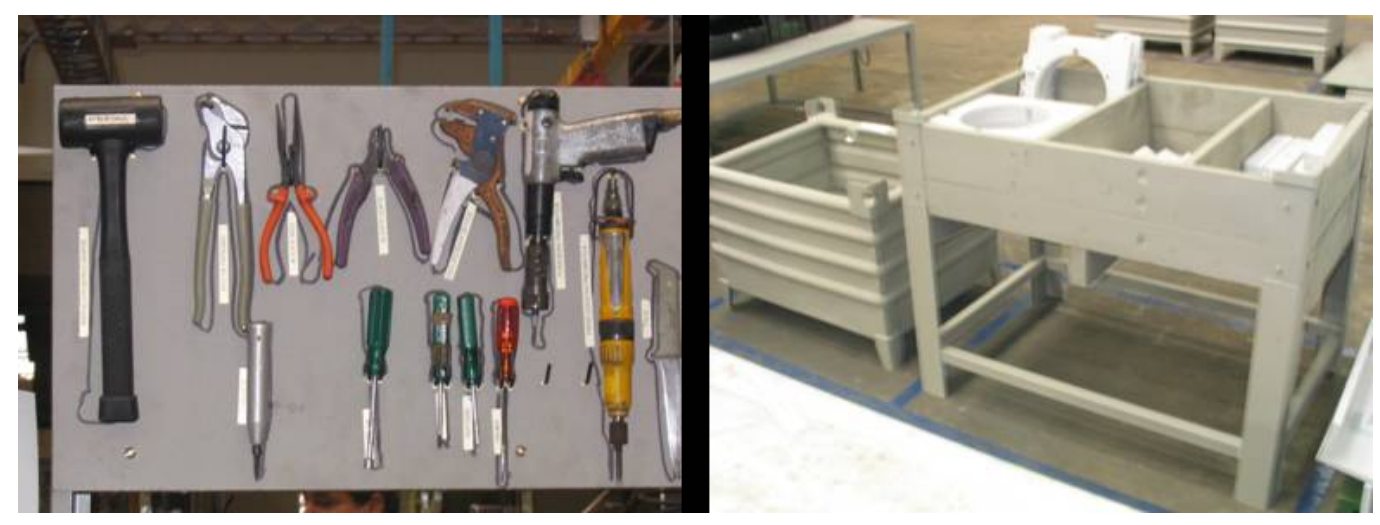

Padronização de Atividades e Processos: foram levantadas as atividades requeridas para o processo de montagem do produto, em seguida estas atividades foram distribuídas e balanceadas entre os postos de trabalho (definidos em linha) de acordo com o ritmo definido pelo mercado (takttime). Esta padronização foi formalizada, documentada e colocada de forma escrita e esquematizada na área de montagem;

Movimentação de Operadores: a movimentação dos operadores (que é uma das categorias de desperdícios) durante o processo de montagem foi analisada. Isto foi feito considerando-se as métricas de quantidade de movimentações realizadas, passos e distância percorrida. O apontamento deste aspecto auxiliou na formulação no novo layout quanto ao local de armazenamento dos itens requeridos para a montagem, bem como o posicionamento dos postos de trabalho na linha; 
Como resultado desta análise e das melhorias implantadas, a quantidade de movimentação, determinada pela necessidade de saída do montador de seu posto, foi diminuída em 70\% (10 vezes para 3 vezes) e a quantidade média de passos diminui de 130 passos para 39 passos. Somente em uma das operações realizadas no processo de montagem, foi possível a diminuição do espaço percorrido pelo operador em 114 metros.

Figura 4 - Aspecto do arranjo físico antes e depois do evento

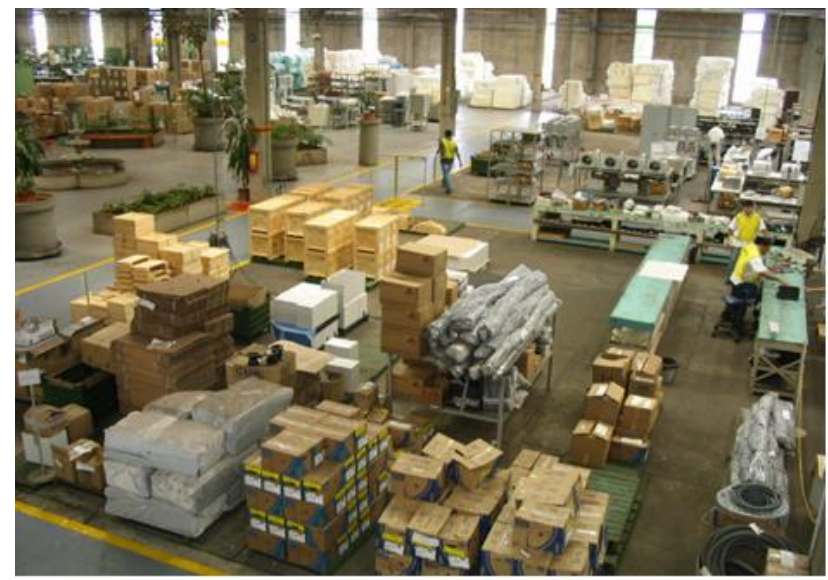

ANTES DO EVENTO

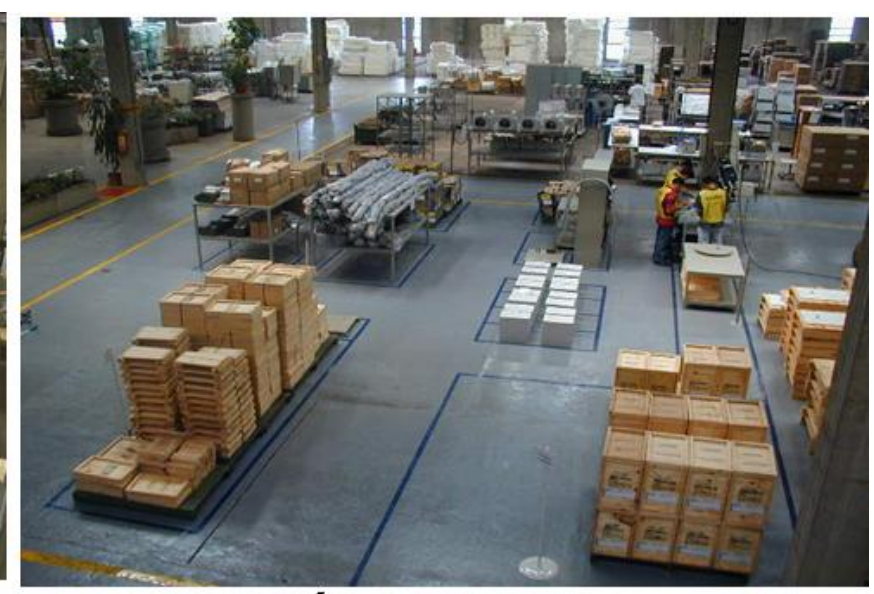

APÓS O EVENTO

Programação Puxada: a programação puxada, por meio da implantação de cartões kanban (uma das principais ferramentas da manufatura enxuta), visava a redução dos desperdícios de superprodução (no processo fornecedor), que resultava em um acúmulo de itens na área de montagem. Mas, ao mesmo tempo, este "estoque de sergurança" não prevenia a ocorrência de paradas do processo, uma vez que a montagem enfrentava o "fenômeno de falta e sobra". Sobravam peças (produzidas em grandes lotes) e faltavam peças (que estavam na "fila" do processo fornecedor interno), o que impediam a completa montagem do produto.

Desta forma, foram identificadas as peças que passariam a serem programadas pelo kanban, identificados seus processos de fabricação, dimensionando-se, em seguida, o tamanho dos supermercados destas peças em função da flexibildidade do processo fornecedor. Em um primeiro momento, o TPT (Toda Parte Todo x) calculado foi de cerca de três dias, com a possibilidade de fabricação de um lote médio muito abaixo do lote médio anteriormente fabricado (15 dias).

Durante o próprio período do evento, foram impressos os cartões, contruídos os quadros de programação e separadas as peças em seus devidos contenedores na área designada para seus supermercados. 
Figura 5 - Equipe implantando quadros kanban e supermercado de itens

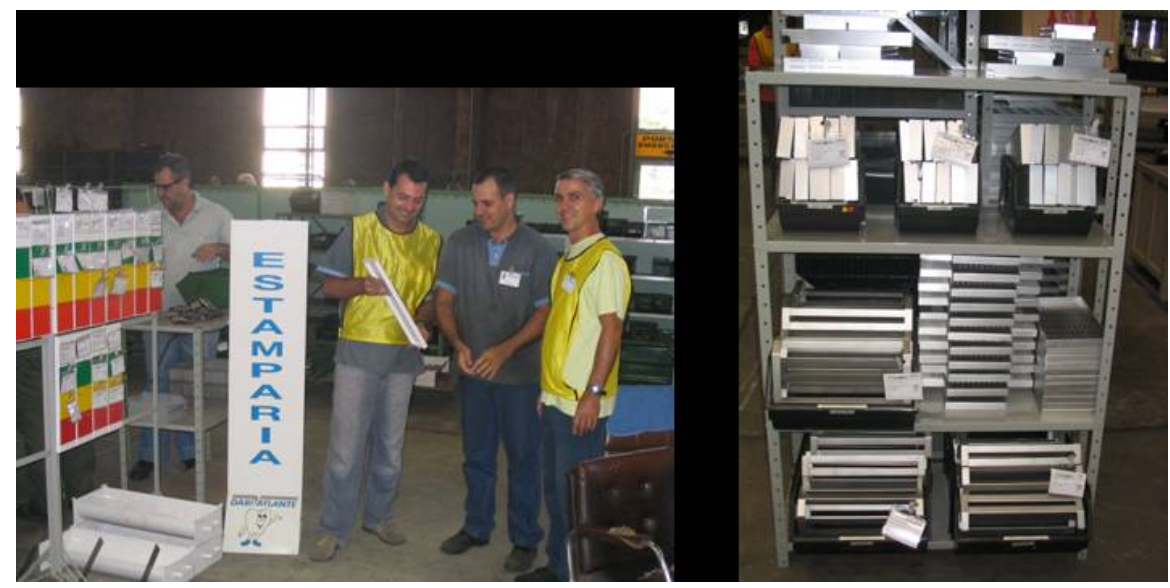

Ergonomia: Aspectos ergonômicos dos operadores também foram considerados no evento kaizen, pois no diagnóstico inicial promovido pela equipe (durante a fase de planejamento) perceberam-se deficiências e potenciais de melhoria neste aspecto.

A fase de treinamento envolveu os operadores de montagem e fornecedores internos do processo, principalmente, quanto à adaptação ao sistema de programação puxada por meio de cartões kanban. Salientou-se a importância do sistema e os benefícios esperados tanto para a organização quanto para a realização do trabalho, de forma mais "linear" e sem sobressaltos devido à falta de peças.

Ainda, enfatizou-se a necessidade de manutenção com relação ao sistema implantado de organização dos itens e padronização das operações de montagem. Mas, ao mesmo tempo, foi estimulada a sensibilização dos operadores quanto à importância do melhoramento contínuo do processo. Ou seja, ainda existiam, certamente, pontos passíveis de melhorias e modificações que poderia ser implantadas pelos próprios operadores.

$\mathrm{Na}$ fase de consolidação, preocupou-se com a ancoragem da melhoria por meio de auditorias, na forma de gerenciamento por rondas. Foi desenvolvido um check-list de verificação, que contemplava itens de organização e limpeza da área, o uso de equipamentos individuais de proteção, gestão visual (aplicação e devida atualização dos indicadores) e a programação puxada (correta utilização do sistema kanban implantado).

As auditorias passaram a funcionar como uma forma de prevenir retrocessos e manter a melhoria, sendo feitas de forma rotineira pelos operadores, líderes de time, supervisores de linha e gerente da planta.

Ao final do período, foi realizada a apresentação das atividades e resultados obtidos para os principais executivos da empresa (incluindo-se diretores, superintendentes e presidente). Percebemos que esta apresentação promoveu efeitos extremamente benéficos ao time de kaizen (por terem seu trabalho reconhecido e com visibilidade junto à administração). 
Além disso, os membros da equipe dos próximos kaizens programados também participaram da apresentação como forma de sensibilização inicial e determinação de padrões de comportamento e resultados esperados.

A celebração mencionada envolve somente os participantes do kaizen promovido (Time de Kaizen), ocorrendo sempre que o mesmo tenha sucesso e atingido (ou superado) os objetivos iniciais, avaliados durante a apresentação dos resultados e visita ao local da implantação.

Não existe uma obrigatoriedade do tipo de celebração, sendo que o time tem um orçamento definido para utilizar nesta celebração (normalmente um almoço ou happy-hour) para comemoração.

É importante enfatizarmos que, desde o início, preocupou-se com a definição de metas que fossem factíveis, mas ao mesmo tempo desafiadoras e agressivas, e que todas as soluções fossem implantadas com a utilização racional dos recursos disponíveis, sem a necessidade de grandes investimentos.

\section{Considerações finais}

O planejamento e execução de "Kaizen Blitz" ou Eventos Kaizen semanais devem ser acompanhados e ancorados em um desenvolvimento preliminar de uma situação futura desejável e/ou idealizada.

Ainda, seja realizando-se Kaizens de processo (pontual) ou de fluxo (sistema) é importante que estas iniciativas façam parte de um plano de ações com uma visão estratégica de médio e longo prazo. Ou seja, que os mesmos não caiam na "banalização" de ações dispersas e desconexas.

Para isso, faz-se necessária a formalização e divulgação ampla de uma visão de longo prazo (Situação Futura Ideal), compartilhada desde as lideranças da empresa até os operadores do gemba (onde o valor para o cliente é realmente gerado).

Muito tem se falado sobre o combate aos desperdícios mais clássicos, tais como: estoques, movimentação, transporte, produtos defeituosos, etc. Mas, nas implantações e eventos kaizen nos quais temos participado, diretores e gerentes têm percebido o grande desperdício de talentos e idéias, que agora encontram espaço para serem colocados em prática.

Se conduzido de um modo estruturado, combatendo-se as reais causas dos problemas, e vinculados a uma visão estratégica de Situação Futura Ideal, o kaizen torna-se uma ferramenta dinâmica e sustentável para a condução da mudança. 


\begin{abstract}
Many companies have been in the journey of implementing the concepts, techniques and tools of the lean manufacturing, mainly, for the expectations of the huge gains already told in the literature, on several aspects such as: internal lead-time reduction, work in progress reduction, increase in productivity etc. However, in many cases, the main found difficulty relies not on the development of the lean system, but on the way of managing the change process on the shop-floor. The aim of this article is to show the application and implementation of the lean production concepts through the kaizen methodology on a medical industry. The concepts used in the implementation process will be presented, as well as some results and conclusions obtained.
\end{abstract}

Key-words: lean manufacturing, kaizen, change management.

\title{
Referências
}

ARAUjO, C. A. C. Desenvolvimento e aplicação de um Método de Implementação de Sistemas de Produção Enxuta utilizando os processos de raciocínio da Teoria das Restrições e o Mapeamento do Fluxo de Valor. Dissertação de mestrado. EESC - USP, 2004.

HINES, P. \& TAYLOR, D. Going Lean. Lean Enterprise Research Centre Text Matters. New York, 2000.

ROTHER, M. \& SHOOK, J. Aprendendo a enxergar. Lean Institute Brasil. São Paulo, 1999.

SMEDS, R. Managing Change towards Lean Enterprises. International Journal of Operations \& Production Management, v.14, n.3 p. 66-82. University Press, 1994

TAPPING, D; LUYSTER, T. \& SHUKER, T. Value Stream Management: eight steps to planning, mapping, and sustaining lean improvements. Productivity Press. New York, 2002.

WOMACK, J. P; JONES, D. T. \& ROOS, D. A máquina que mudou o mundo. Campus. 5a Edição. Rio de Janeiro, 1992.

WOMACK, J. P. \& JONES, D. T. A mentalidade enxuta nas empresas: elimine o desperdício e crie riqueza. 4a Edição. Rio de Janeiro, 1998.

\section{Dados completos do primeiro autor}

Nome completo: Cesar Augusto Campos de Araujo

Filiação institucional: Escola de Engenharia de São Carlos - EESC - USP

Departamento: Departamento de Engenharia de Produção

Função ou cargo ocupado: Doutorando

Endereço: R. Vicente J. Freire, 999, Casa 05, Vila Xavier, Araraquara, SP, Brasil, 14810-038.

Telefones para contato: (16) 3362-6297

e-mail: cesar@hominiss.com.br

Recebido para publicação em: 28/11/2005

Aceito para publicação em: 05/04/2006 